\title{
An Alternative technique to Gauss Elimination Method for Determinants: Integers Version
}

\author{
Najm Obaid Salim Alghazali ${ }^{1}$ \\ ${ }^{1}$ Civil Engineering Department, Engineering College, Babylon University, Iraq.
}

\begin{abstract}
ARTICLE INFO
Keywords:

Determinants, Gauss

elimination method, inverse of a matrix, The Greatest Common

Divisor Laplace

expansion method, linear

system of algebraic

equations, singular

matrix, upper triangular

determinant.
\end{abstract}

\begin{abstract}
In this research an alternative technique to Gauss Elimination Method forDeterminants is presented.It gives exact determinants.It is free of fractions, free of round off errors and can be applied for all types of square matrices. This alternative technique is illustrated through four different examples.
\end{abstract}

\section{Introduction}

In civil engineering applications, the linear system of algebraic equations, $\mathbf{A X}=\mathbf{B}$, arises, for example, in the solution of ordinary and partial differential equations, interpolation, curve fitting, networks of roads and Truss problem. If the determinant of the coefficient matrix $|\mathrm{A}| \neq 0$, the system has unique solution and if $|\mathrm{A}|=0$, the system has either no solution or infinitely many solutions [1]. The square matrix A has inverse if the determinant $|\mathrm{A}| \neq 0$, and it is not invertible if $|\mathrm{A}|=0$ [2]. Thus, before using analytical or numerical methods to solve the linear system of algebraic equations or to find $\mathbf{A}^{\mathbf{- 1}}$ it is better to find the determinant value.

Determinants of $2^{\text {nd }}$ order are evaluated analytically by the diagonal method. Determinants of $3^{\text {rd }}$ order are evaluated analytically by the diagonal method or Laplace expansion method (also called the cofactors method) ([2]-[4]). Determinants of order 4 or higher can be reduced to $3^{\text {rd }}$ or $2^{\text {nd }}$ ordered determinants using Laplace expansion method ([2], [3], [5]). Because of the high amount of work needed to reduce the high ordered determinants to $3^{\text {rd }}$ or $2^{\text {nd }}$ ordered determinants, Laplace expansion method is considered impractical and is not recommended for high ordered determinants ([6], [7]). Therefore, for high ordered determinants numerical methods are used.

Corresponding Author E-Mail Address: dr.nalghazali@gmail.com 
Gauss elimination method is a numerical method used to find the value of a determinant $|\mathrm{A}|$. The basic idea of Gauss elimination method is transforming the original determinant $|\mathrm{A}|$ to upper triangular one $|\mathrm{U}|$ and then finding the determinant $|\mathrm{A}|$ value by multiplying the main diagonal numbers of $|\mathrm{U}|$. If partial pivoting is used then the value of the determinant is the negative of the original determinant.

Classification Gauss elimination method involves fractions (if hand calculations are used) or decimal numbers through transformation process of $|\mathrm{A}|$ to $|\mathrm{U}|$. Dealing with fractions is not comfortable and working with decimal numbers may lead to round off errors which lead to get approximate values of determinants. For example, by using Gauss elimination method the determinant value of

$$
|\mathbf{A}|=\left|\begin{array}{cc}
0.05 & -0.03 \\
-0.05 & 0.03
\end{array}\right|
$$

is $|\mathrm{A}|=2.77556 \mathrm{E}-18$ ([8], Example, Page 86). It is clear that the analytical evaluation of the determinant using the diagonal method gives $|\mathrm{A}|=0$. This is due to the round off errors result from the numerical technique used. Using the alternative technique presented in this research, we get precisely $|\mathrm{A}|=0$.

In this research an alternative technique to Gauss Elimination Method for determinants is presented. It is free of fractions, free of round off errors, reliable and can be applied for all types of square matrices. All the entries from the original determinant $|\mathrm{A}|$ to $|\mathrm{U}|$ are integers without fractions or decimal numbers and this is the reason of calling it "Integers Version." The determinant value is a rational number found at the last step. The result is either ending or repeating number. Therefore, we get exact determinants.

\section{Literature review and Comments}

The following are the techniques used to find the determinant value by Gauss Elimination Method (in this research it is called the traditional Gauss Elimination Method for determinants):

2.1 The determinant of a square matrix is transformed to upper triangular determinant with no row interchanges (partial pivoting) [6]. Then, the product of the main diagonal elements of the upper triangular determinant gives the determinant value. This technique works well when all the entries from the original determinant $|\mathrm{A}|$ to $|\mathrm{U}|$ are integers and there is no zero pivot number, otherwise this technique will involve fractions or decimal numbers which may lead to round off errors. Thus, approximate value of a determinant is obtained.

2.2 To reduce the round off errors in the previous technique, Gauss Elimination Method with partial pivoting is used to transform the determinant of a square matrix to upper triangular determinant, ([2], [8]-[12]). In this technique, the determinant changes sign every time a row is switched. This technique may involve fractions or decimal numbers and thus it reduces the round off errors but not eliminate them.

2.3 In this technique the original matrix is transformed to upper triangular matrix with all main diagonal elements equal to 1 except the last element $u_{n n}$ using properties of determinants [13]. This technique may involve fractions or decimal numbers and thus it is subject to round off errors and needs a lot of work.

2.4 In this technique the determinant is transformed to unit upper triangular determinant (the main diagonal contains all 1's) using pproperties of determinants ([14], [15]). This method involves fractions or decimal numbers and thus it may be subject to round off errors. 
2.5 In this method the square matrix A is factored according to Doolittle's factorization method PA = $\mathrm{LU}$, where $\mathrm{P}$ is a permutation matrix, $\mathrm{L}$ is a unit lower triangular matrix (with ones on the main diagonal) and $U$ is upper triangular matrix with the pivots on its main diagonal ([7], [16]-[24]). This method is adopted by MATLAB ([25]-[27]. An advantage of this two-step approach is that if further linear systems involving $\mathbf{A}$ are to be solved then the LU factors can be reused, with a saving in computation [25]. The computation of the determinant $|\mathrm{A}|$ is affected by rounding errors in general [25].

It is to note that this literature review involves only the techniques used to find the determinant value by the traditional Gauss Elimination Method. Other methods, such as Sivanandam and Bai method [28] which is also subject to rounding errors, are outside the scope of the present research.

\section{The Alternative technique to Gauss Elimination Method for Determinants: Integers Version}

In this alternative technique the determinant $|\mathbf{A}|$ is transformed to upper triangular determinant $|\mathbf{U}|$ using properties of determinants and without pivoting (partial or complete) or scaling. In applying this technique there is no chance to the hand calculator or the computer to round off the numbers and thus we get exact determinants. The elements of the original determinant $|\mathbf{A}|$ must be integers and all elements in any stage through transforming process of the original determinant to upper triangular one are integers. The value of the upper triangular determinant will be integer since all the main diagonal elements are integers. By this technique we avoid round off errors. The value of the determinant $|\mathrm{A}|$ is found at the last step. It is rational number and the result will be a number which is of ending or repeating type.

The following is the procedure of the alternative technique to Gauss Elimination Method for Determinants: Integers Version

1. The elements of the original determinant $|\mathbf{A}|$ must be integers.

This is a difference between the alternative and the traditional techniques of Gauss Elimination Method for Determinants. The traditional technique of Gauss Elimination Method for Determinants does not impose that the elements of the original determinant $|\mathbf{A}|$ must be integers.

2. At any stage of the solution process the main diagonal element (the pivot number) $a_{\mathrm{ii}}$ must be integer and $\neq 0$.

This is a difference between the alternative and the traditional techniques of Gauss Elimination Method for Determinants. The traditional technique of Gauss Elimination Method for Determinants does not impose that the main diagonal element (the pivot number) $a_{\mathrm{ii}}$ must be integer.

If the main diagonal element $\mathrm{a}_{\mathrm{ii}}=0$ then exchange row $\mathrm{i}$ with any row below it for which $\mathrm{a}_{\mathrm{mi}} \neq 0$ and set $S_{i}=1$ where $S_{i}$ refers to the change of the determinant sign. This is based on the determinant property: If two rows are interchanged, the new determinant is the negative of the old one. If there is no rows interchange set $S_{i}=0$. If all the elements below $a_{\mathrm{ii}}=0$ are zeros, then $|\mathbf{A}|=0$.

3. Transform $|\mathbf{A}|$ to upper triangular determinant $|\mathbf{U}|$ using the following equation for every row except the pivot row 


$$
\left.\left.\mathrm{R}_{\mathrm{i}}\right)_{\text {new }}=\mathrm{R}_{\mathrm{i}}\right)_{\text {old }}-\mathrm{k}_{\mathrm{mi}} \mathrm{R}_{\mathrm{k}}
$$

Where $\left.R_{i}\right)_{\text {new }}$ are the new elements of any row, $\left.R_{i}\right)_{\text {old }}$ are the old elements of the same row, $R_{k}$ are the elements of the pivot row and $\mathrm{k}_{\mathrm{mi}}=\mathrm{a}_{\mathrm{mi}} / \mathrm{a}_{\mathrm{ii}}$ where $\mathrm{a}_{\mathrm{ii}}$ is the pivot element and $\mathrm{a}_{\mathrm{mi}}$ is the element below $\mathrm{a}_{\mathrm{ii}}$ of row $\left.\mathrm{R}_{\mathrm{i}}\right)_{\text {old. }}$. This equation is based on the determinant property: The determinant value is unchanged if a row is added to another row multiplied by a scalar.

$\mathrm{k}_{\mathrm{mi}}$ must be integer. If $\mathrm{k}_{\mathrm{mi}}$ is not integer, multiply $\left.\mathrm{R}_{\mathrm{i}}\right)_{\text {old }}$ by $\left|\mathrm{a}_{\mathrm{ii}}\right|$ and set $\mathrm{M}_{\mathrm{i}}=\left|\mathrm{a}_{\mathrm{ii}}\right|$ where $\mathrm{M}_{\mathrm{i}}$ refers to the multiplication of the determinant by the constant $\left|\mathrm{a}_{\mathrm{ii}}\right|$. This is based on the determinant property: If one row is multiplied by a constant, the new determinant is the old one multiplied by that constant. Then use Eq.1. By this procedure $\mathrm{k}_{\mathrm{mi}}$ will always be integer. This is a difference between the alternative and the traditional techniques of Gauss Elimination Method for Determinants. The traditional technique of Gauss Elimination Method for Determinants does not impose that $\mathrm{k}_{\mathrm{mi}}$ must be integer.

4. Find $|\mathbf{A}|$ value using Eq.2

$$
|\mathbf{A}|=\frac{\mathrm{S}|\mathbf{U}|}{\mathrm{M}}
$$

Where

$\mathrm{S}$ is the function counts sign changes, $\mathrm{S}=(-1)^{\sum S_{i}}$. If $\Sigma \mathrm{S}_{\mathrm{i}}=$ odd number then $\mathrm{S}=-1$ and if $\Sigma \mathrm{S}_{\mathrm{i}}=$ zero or even number then $S=1$.

$$
|\mathrm{U}|=\prod_{i=1}^{n} u_{i i}
$$

This is based on the determinant property: The value of upper triangular determinant is equal to the product of its major diagonal elements.

$\mathrm{M}$ is the multiplication function $\left(=\prod_{i=1}^{n} M_{i}\right)$. For the case of no multiplication set $\mathrm{M}=1$.

\section{The use of Greatest Common Divisor (GCD)}

This is an optional step.

For big determinant entries we can use the greatest common divisor since all the elements in any step are integers. This will make the big numbers smaller and it is especially useful to those using hand calculations with the aid of hand calculators. For the case of using the greatest common divisor, Eq. 2 is modified to Eq. 4

$$
|\mathbf{A}|=\frac{\mathrm{S}|\mathbf{U}| \mathrm{G}}{\mathrm{M}}
$$


where $\mathrm{G}=$ the greatest common divisor (GCD). This is based on the determinant property: If one row is multiplied by a constant, the new determinant is the old one multiplied by that constant. Example 4 shows the use of the greatest common divisor.

\section{Examples}

The Alternative technique to Gauss Elimination Method for Determinants: Integers Version is applied to many determinants with different orders (small and high ordered determinants) and excellent results were obtained. For this research, simple examples are selected in order to clarify this alternative technique.

Example 1: Application for the case $\mathbf{S}=\mathbf{1}$ and $\mathbf{M}=\mathbf{1}$ ([23], Example 1, Page 713 with modification)

$$
\text { Evalate }|\mathbf{A}|=\left|\begin{array}{ccc}
0.1 & 0.2 & 0.3 \\
4 & 5 & 6 \\
7 & 8 & 0
\end{array}\right|
$$

\section{Solution}

According to step 1 of the procedure of the alternative technique, the elements of the original determinant must be integers, we multiply $\mathrm{R}_{1}$ by 10 to get

$$
|\mathbf{B}|=\left|\begin{array}{lll}
1 & 2 & 3 \\
4 & 5 & 6 \\
7 & 8 & 0
\end{array}\right|
$$

\begin{tabular}{|c|c|c|c|c|c|c|}
\hline \multicolumn{3}{|c|}{$\begin{array}{l}\text { (1) The original } \\
\text { determinant }|\mathbf{B}|\end{array}$} & Notes & $\mathrm{k}$ & M & $\mathrm{S}$ \\
\hline 1 & 2 & 3 & $\mathrm{R}_{1}^{(1)}$ & \multirow{4}{*}{$\begin{array}{l}\mathrm{k}_{21}= \\
4 \\
\mathrm{k}_{31}= \\
7\end{array}$} & & \\
\hline 4 & 5 & 6 & $\mathrm{R}_{2}^{(1)}$ & & & \\
\hline \multirow[t]{2}{*}{7} & 8 & 0 & $\mathrm{R}_{3}{ }^{(1)}$ & & & \\
\hline & \multicolumn{2}{|c|}{ (2) } & & & $\begin{array}{c}\mathrm{M}_{1}= \\
1\end{array}$ & $\begin{array}{c}S_{1}= \\
0\end{array}$ \\
\hline 1 & 2 & 3 & \multirow{3}{*}{$\begin{array}{l}\mathrm{R}_{2}^{(2)}=\mathrm{R}_{2}{ }^{(1)}- \\
4 \times \mathrm{R}_{1}{ }^{(1)} \\
\mathrm{R}_{3}^{\left({ }^{(2)}\right.}=\mathrm{R}_{3}{ }^{(1)}-7 \\
\mathrm{x} \mathrm{R}_{1}{ }^{(1)}\end{array}$} & \multirow[b]{3}{*}{$\begin{array}{l}\mathrm{k}_{32}= \\
2\end{array}$} & & \\
\hline 0 & -3 & -6 & & & & \\
\hline 0 & -6 & -21 & & & & \\
\hline \multicolumn{3}{|c|}{ (3) } & & & $\begin{array}{c}\mathrm{M}_{2}= \\
1\end{array}$ & $\begin{array}{c}\mathrm{S}_{2}= \\
0\end{array}$ \\
\hline $\begin{array}{l}1 \\
0\end{array}$ & $\begin{array}{c}2 \\
-3\end{array}$ & $\begin{array}{c}3 \\
-6\end{array}$ & & & & \\
\hline
\end{tabular}

We find the value of the determinant $|\mathrm{B}|$ then we find the value of the determinant $|\mathrm{A}|$ as follows: 


\begin{tabular}{|c|c|c|c|c|}
\hline 0 & 0 & $\begin{array}{l}\mathrm{R}_{3}^{(3)}=\mathrm{R}_{3}^{(2)}-2 \\
\mathrm{x} \mathrm{R}_{2}^{(2)}\end{array}$ & & \\
\hline & $X-3 X-9=27$ & & $\begin{array}{c}\mathrm{M}= \\
1\end{array}$ & $\begin{array}{r}\Sigma \mathrm{S}_{\mathrm{i}} \\
0 \\
0\end{array}$ \\
\hline
\end{tabular}

$$
\begin{aligned}
\Sigma \mathrm{S}_{\mathrm{i}} & =\mathrm{S}_{1}+\mathrm{S}_{2}=0+0=0 . \text { Since } \Sigma \mathrm{S}_{\mathrm{i}}=0 \text { then } \mathrm{S}=(-1)^{\sum \mathrm{s}_{\mathrm{i}}}=1 . \\
\mathrm{M} & =\prod_{i=1}^{n} M_{i}=\mathrm{M}_{1} \mathrm{X} \mathrm{M}_{2}=1 \times 1=1 . \\
|\mathbf{B}| & =\frac{\mathrm{S}|\mathbf{U}|}{\mathrm{M}}=\frac{1 \mathrm{X} 27}{1}=27 \\
|\mathbf{A}| & =|\mathbf{B}| / 10=27 / 10=2.7 .
\end{aligned}
$$

This is based on the determinant property: If one row is multiplied by a constant, the new determinant is the old one multiplied by that constant.

\section{Notes:}

1. $\mathrm{R}_{1}{ }^{(1)}$ and $\mathrm{R}_{1}{ }^{(2)}$ mean row 1 at first and second stages respectively. This definition is also used for other rows. Rows with blank definition mean that there are no changes occur to these rows in these stages.

2. The sequence of calculations and details are as follows:

In stage 1:

$\mathrm{k}_{21}=\mathrm{a}_{21} / \mathrm{a}_{11}=4 / 1=4$ and $\mathrm{k}_{31}=\mathrm{a}_{31} / \mathrm{a}_{11}=7 / 1=7 . \mathrm{S}_{1}=0$ since there is no rows interchange and $\mathrm{M}_{1}=$ 1 because $\mathrm{k}_{21}$ and $\mathrm{k}_{31}$ are integers.

In stage 2:

The first row elements $R_{1}{ }^{(2)}$ are the same as the first row elements in stage $1\left(R_{1}{ }^{(1)}\right)$, thus $R_{1}{ }^{(2)}$ is not defined and the space left blank.

For the second row $\mathrm{R}_{2}{ }^{(2)}$ : the details of $\mathrm{R}_{2}{ }^{(2)}=\mathrm{R}_{2}{ }^{(1)}-4 \times \mathrm{R}_{1}{ }^{(1)}$ are

\begin{tabular}{llll}
$\mathrm{R}_{2}{ }^{(1)}$ & 4 & 5 & 6 \\
$-4 \mathrm{X}$ & $-4 \mathrm{X}$ & & \\
$\mathrm{R}_{1}{ }^{(1)}$ & $(1$ & 2 & $3)$ \\
\hline $\mathrm{R}_{2}{ }^{(2)}$ & 0 & - & -6
\end{tabular}

For the third row $\mathrm{R}_{3}{ }^{(2)}$ : the details of $\mathrm{R}_{3}^{(2)}=\mathrm{R}_{3}{ }^{(1)}-7 \times \mathrm{R}_{1}{ }^{(1)}$ are 


\begin{tabular}{llll}
$\mathrm{R}_{3}{ }^{(1)}$ & 7 & 8 & 0 \\
& & & \\
$-7 \mathrm{X}$ & $-7 \mathrm{X}$ & & \\
$\mathrm{R}_{1}{ }^{(1)}$ & $(1$ & 2 & $3)$ \\
\hline $\mathrm{R}_{3}^{(2)}$ & 0 & 6 & 21 \\
$\mathrm{k}_{32}=\mathrm{a}_{32} / \mathrm{a}_{22}=-6 /-3=2 . \mathrm{M}_{2}=1$ because $\mathrm{k}_{32}$ is integer. \\
$\mathrm{S}_{2}=0$ since there is no rows interchange.
\end{tabular}

In stage 3:

$\mathrm{R}_{1}^{(3)}$ and $\mathrm{R}_{2}^{(3)}$ elements are the same as $\mathrm{R}_{1}{ }^{(1)}$ and $\mathrm{R}_{2}{ }^{(2)}$ respectively, therefore they are not defined and the spaces left blanks.

For the third row $\mathrm{R}_{3}{ }^{(3)}$ : the details of $\mathrm{R}_{3}{ }^{(3)}=\mathrm{R}_{3}{ }^{(2)}-2 \times \mathrm{R}_{2}{ }^{(2)}$ are

\begin{tabular}{llll}
$\mathrm{R}^{(2)}$ & 0 & 6 & 21 \\
& $-2 X$ & - & - \\
$\mathrm{R}_{2}^{(2)}$ & $(0$ & 3 & $6)$ \\
\hline $\mathrm{R}^{(3)}$ & 0 & 0 & -9
\end{tabular}

In this stage we obtain upper triangular determinant, so we compute its value as shown in the previous table. The remained calculations for finding the value of the determinant $|\mathrm{A}|$ are shown below the previous table.

3. In this example the alternative and the traditional techniques of Gauss Elimination Method for Determinants give the same value of the determinant because all the entries from the beginning to the end are integers.

Example 2: Singular matrix ([27], Example, Page 88, [29], Example, Page 665)

$$
\text { Evalate }|\mathbf{A}|=\left|\begin{array}{lll}
1 & 2 & 3 \\
4 & 5 & 6 \\
7 & 8 & 9
\end{array}\right|
$$




\section{Solution}

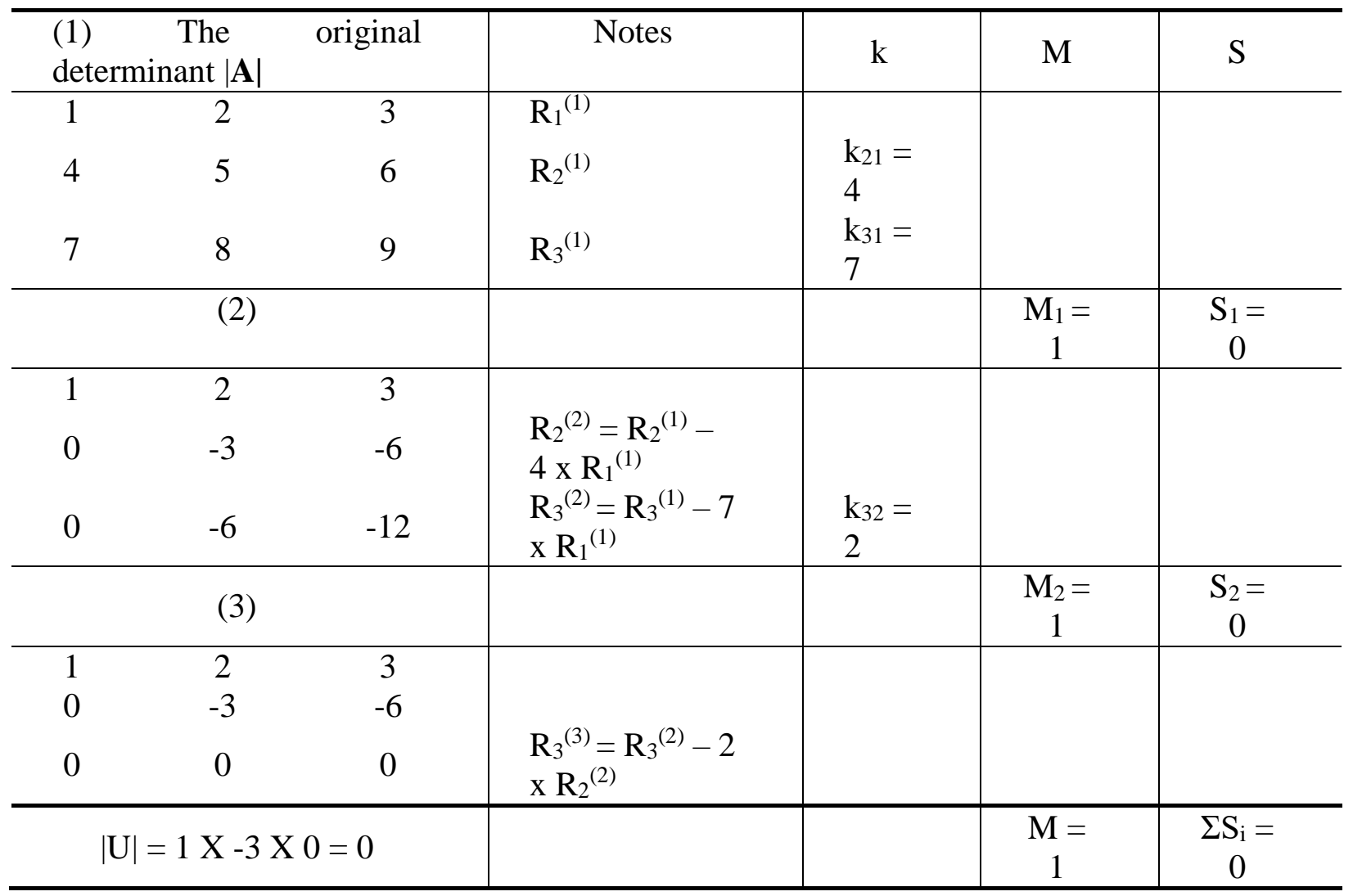

Since $\Sigma \mathrm{S}_{\mathrm{i}}=0$, then $\mathrm{S}=(-1)^{\sum s_{i}}=1$.

$$
\mathrm{M}=\prod_{i=1}^{n} M_{i}=\mathrm{M}_{1} \mathrm{XM}_{2}=1 \mathrm{X} 1=1 .
$$

$|\mathbf{A}|=\frac{\mathrm{S}|\mathbf{U}|}{\mathrm{M}}=\frac{1 \mathrm{X} 0}{1}=0$

Note: The sequence of calculations and details are like that of Example 1.

Discussion: This example was solved using MATLAB and the following message appeared "Warning: Matrix is close to singular or badly scaled." Thus, MATLAB does not exactly tell us whether the matrix $A$ is singular. This is due to the round off errors result from the numerical method used. By using Excel we obtain $|\mathrm{A}|=6.66134 \mathrm{E}-16$. This is also due to the round off errors result from the numerical method used.

Another subject relates to small values of determinants is the ill-conditioned matrix for which the determinant value is very small [5]. Small determinant does not mean that the matrix near singularity [18]. The Vandermode matrices tend to be ill-conditioned [21]. The value of the Vandermode determinant of a system of linear algebraic equations is small but there is a solution to the linear 
system of algebraic equations. Thus, obtaining $|\mathrm{A}| \cong 0$ does not mean that the system has either many solutions or no solution at all. In civil engineering applications, for example in the networks of roads, we need exactly to know if $|\mathrm{A}|=0$ in order to investigate the many solutions of the problems. The proposed alternative technique to Gauss Elimination Method for Determinants avoids the round off errors and enables us to get exactly zero value for the determinant of a singular matrix and a small value for ill-conditioned matrix.

Example 3: Application of S and M ([6], Example 1.9, Page 47)

$$
\text { Evalate }|\mathbf{A}|=\left|\begin{array}{ccc}
0 & 2 & 1 \\
4 & 1 & -1 \\
-2 & 3 & -3
\end{array}\right|
$$

\section{Solution}

\begin{tabular}{|c|c|c|c|c|c|c|}
\hline \multicolumn{2}{|c|}{$\begin{array}{ll}(1) \quad \text { The } \\
\text { determinant }|\mathbf{A}|\end{array}$} & \multirow{2}{*}{$\begin{array}{r}\text { original } \\
1\end{array}$} & Notes & \multirow[t]{4}{*}{$\mathrm{k}$} & \multirow[t]{4}{*}{ M } & \multirow[t]{4}{*}{$\mathrm{S}$} \\
\hline 0 & 2 & & $\mathrm{R}_{1}{ }^{(1)}$ & & & \\
\hline 4 & 1 & -1 & $\mathrm{R}_{2}{ }^{(1)}$ & & & \\
\hline-2 & 3 & -3 & $\mathrm{R}_{3}{ }^{(1)}$ & & & \\
\hline \multicolumn{3}{|c|}{ (2) } & & & $\begin{array}{c}\mathrm{M}_{1}= \\
1\end{array}$ & $\begin{array}{c}\mathrm{S}_{1}= \\
1\end{array}$ \\
\hline 4 & 1 & -1 & \multirow{3}{*}{$\begin{array}{l}\mathrm{R}_{1}^{(2)}=\mathrm{R}_{2}^{(1)} \\
\mathrm{R}_{2}^{(2)}=\mathrm{R}_{1}^{(1)}\end{array}$} & \multirow{4}{*}{$\begin{array}{l}\mathrm{k}_{21}=0 \\
\mathrm{k}_{31}=-2 / 4\end{array}$} & & \\
\hline 0 & 2 & 1 & & & & \\
\hline \multirow[t]{2}{*}{-2} & 3 & -3 & & & $\begin{array}{c}\mathrm{M}_{23}= \\
4\end{array}$ & \\
\hline & \multicolumn{2}{|l|}{ (3) } & & & $\begin{array}{c}\mathrm{M}_{2}= \\
4\end{array}$ & $\begin{array}{c}\mathrm{S}_{2}= \\
0\end{array}$ \\
\hline 4 & 1 & -1 & \multirow{4}{*}{$\mathrm{R}_{3}{ }^{(2)}=4 \mathrm{X} \mathrm{R}_{3}{ }^{(1)}$} & \multirow{4}{*}{$\begin{array}{l}\mathrm{k}_{21}=0 \\
\mathrm{k}_{31}=-2\end{array}$} & & \\
\hline 0 & 2 & 1 & & & & \\
\hline-8 & 12 & -12 & & & & \\
\hline & (4) & & & & $\begin{array}{c}\mathrm{M}_{3}= \\
1\end{array}$ & $\begin{array}{c}\mathrm{S}_{3}= \\
0\end{array}$ \\
\hline 4 & 1 & -1 & \multirow{4}{*}{$\begin{array}{l}\mathrm{R}_{2}^{(3)}=\mathrm{R}_{2}^{(2)}-(0) \\
\mathrm{R}_{1}^{(2)} \\
\mathrm{R}_{3}^{(3)}=\mathrm{R}_{3}^{(2)}-(-2) \\
\mathrm{R}_{1}{ }^{(2)}\end{array}$} & \multirow{4}{*}{$\begin{array}{l}\mathrm{k}_{32}=14 / 2 \\
=7\end{array}$} & & \\
\hline 0 & 2 & 1 & & & & \\
\hline \multirow[t]{2}{*}{0} & 14 & -14 & & & & \\
\hline & (5) & & & & $\begin{array}{c}\mathrm{M}_{4}= \\
1\end{array}$ & $\begin{array}{c}\mathrm{S}_{4}= \\
0\end{array}$ \\
\hline 4 & 1 & -1 & & & & \\
\hline 0 & 2 & 1 & & & & \\
\hline 0 & 0 & -21 & $\begin{array}{l}\mathrm{R}_{3}{ }^{(4)}=\mathrm{R}_{3}^{(3)}-(7) \\
\mathrm{R}_{2}^{(3)}\end{array}$ & & & \\
\hline & $\mathrm{X} 2 \mathrm{X}$ & $=-168$ & & & $\begin{array}{c}\mathrm{M}= \\
4\end{array}$ & $\begin{array}{c}\Sigma \mathrm{S}_{\mathrm{i}}= \\
1\end{array}$ \\
\hline
\end{tabular}




$$
\begin{aligned}
\Sigma \mathrm{S}_{\mathrm{i}} & =\mathrm{S}_{1}+\mathrm{S}_{2}+\mathrm{S}_{3}+\mathrm{S}_{4}=1+0+0+0=1 . \text { Since } \Sigma \mathrm{S}_{\mathrm{i}}=1 \text { then } \mathrm{S}=(-1)^{\sum \mathrm{s}_{\mathrm{i}}}=-1 . \\
\mathrm{M} & =\prod_{i=1}^{n} M_{i}=\mathrm{M}_{1} \mathrm{X} \mathrm{M}_{2} \mathrm{X} \mathrm{M}_{3} \mathrm{X} \mathrm{M}_{4}=1 \mathrm{X} 4 \mathrm{X} 1 \mathrm{X} 1=4 . \\
|\mathbf{A}| & =\frac{\mathrm{S}|\mathbf{U}|}{\mathrm{M}}=\frac{-1 \mathrm{X}(-168)}{4}=42
\end{aligned}
$$

\section{Notes:}

1. In stage 1 of the solution $\mathrm{a}_{11}=0$, therefore, according to step 2 of the procedure of the alternative technique, $R_{1}$ and $R_{2}$ are interchanged, as shown in stage 2 , and $S_{1}=1$.

2. In stage 2 of the solution $\mathrm{k}_{31}=\mathrm{a}_{31} / \mathrm{a}_{11}=-2 / 4=-0.5$. As it is not integer, then, according to step 3 of the procedure of the alternative technique, $R_{3}$ is multiplied by $4\left(=\left|a_{11}\right|\right)$ as shown in stage $3 . M_{23}=4$ means in stage $2 R_{3}$ is multiplied by 4 and $M_{2}=4$ means all the multiplications in stage 2 are equal to 4 .

The remained calculations for finding the value of the determinant $|\mathrm{A}|$ are as that for the previous examples.

Example 4: Application of the Greatest Common Divisor (GCD) ([6], Example 1.14, Page 55)

$$
\text { Evalate }|\mathbf{A}|=\left|\begin{array}{ccc}
80 & -20 & -20 \\
-20 & 40 & -20 \\
-20 & -20 & 130
\end{array}\right|
$$

\section{Solution}

At first we find the GCD for rows and columns of the original determinant, and then the better one is selected.

\begin{tabular}{|c|c|c|c|c|c|c|c|}
\hline \multicolumn{3}{|c|}{ The original } & $\begin{array}{c}\text { GC } \\
\text { determinant }|\mathrm{A}|\end{array}$ & $\begin{array}{c}\text { GCD } \\
\text { for } \\
\text { rows }\end{array}$ & $\begin{array}{c}\text { for } \\
\text { column } \\
\text { s }\end{array}$ & \multicolumn{3}{c|}{$|\mathrm{B}|$ After using GCD for } \\
rows
\end{tabular}

The previous table shows that for this example GCD for rows = GCD for columns. If GCD for rows is selected then the resulting determinant is $|\mathrm{B}|$ shown in the previous table which has small entries. 
We first find the value of $|\mathrm{B}|$ then we find the value of $|\mathrm{A}|$. We can now find the value of $|\mathrm{B}|$ using GCD or without using GCD since the entries of $|B|$ are small. The following is finding the value of $|\mathrm{B}|$ using GCD to clarify the details. Only the GCD for rows is used in the evaluation of $|\mathrm{B}|$ starting from the first pivot row to the last pivot row. This will reduce $a_{i i}$ of the pivot row if we need to multiply other rows by this number and reduce the elements values of the rows below the pivot row.

\begin{tabular}{|c|c|c|c|c|c|c|c|}
\hline \multicolumn{3}{|c|}{ (1) Determinant $|\mathbf{B}|$} & \multirow{2}{*}{$\frac{\text { Notes }}{\mathrm{R}_{1}^{(1)}}$} & \multirow[t]{2}{*}{$\mathrm{k}$} & \multirow[t]{2}{*}{$\mathrm{M}$} & \multirow[t]{2}{*}{$\mathrm{G}$} & \multirow[t]{2}{*}{$\mathrm{S}$} \\
\hline 4 & -1 & -1 & & & & & \\
\hline- & 2 & -1 & & $\mathrm{k}_{21}$ & $\mathrm{M}_{12}$ & & \\
\hline 1 & & & $\mathrm{R}_{2}^{(1)}$ & $\begin{array}{l}=- \\
1 / 4\end{array}$ & $=4$ & & \\
\hline- & -2 & 13 & & $\mathrm{k}_{31}$ & $\mathrm{M}_{13}$ & & \\
\hline 2 & & & $\mathrm{R}_{3}^{(1)}$ & $\begin{array}{l}=- \\
2 / 4\end{array}$ & $=4$ & & \\
\hline & $(2)$ & & & & $\begin{array}{c}\mathrm{M}_{1} \\
= \\
16\end{array}$ & $\begin{array}{c}\mathrm{G}_{1} \\
= \\
1\end{array}$ & $\begin{array}{l}\mathrm{S}_{1} \\
=0\end{array}$ \\
\hline 4 & -1 & -1 & & & & & \\
\hline- & 8 & -4 & $\mathrm{R}_{2}^{(2)}=4 \mathrm{X}$ & $\mathrm{k}_{21}$ & & & \\
\hline 4 & & & $\mathrm{R}_{1}^{(1)}$ & $\begin{array}{l}=- \\
1\end{array}$ & & & \\
\hline- & -8 & 52 & $\mathrm{R}_{3}^{(2)}=4 \mathrm{X}$ & $\mathrm{k}_{31}$ & & & \\
\hline 8 & & & $\mathrm{R}_{1}^{(1)}$ & $\begin{array}{l}=- \\
2\end{array}$ & & & \\
\hline & (3) & & & & $\begin{array}{l}\mathrm{M}_{2} \\
=1\end{array}$ & $\begin{array}{c}\mathrm{G}_{2} \\
= \\
1\end{array}$ & $\begin{array}{l}\mathrm{S}_{2} \\
=0\end{array}$ \\
\hline 4 & -1 & -1 & & & & & \\
\hline 0 & 7 & -5 & $\begin{array}{l}\mathrm{R}_{2}^{(3)}=\mathrm{R}_{2}^{(2)}- \\
(-1) \mathrm{X} \mathrm{\textrm {R } _ { 1 } ^ { ( 1 ) }}\end{array}$ & & & & \\
\hline 0 & - & 50 & $\mathrm{R}_{3}^{(3)}=\mathrm{R}_{3}^{(2)}-$ & & & $\mathrm{G}$ & \\
\hline & 10 & & $(-2) \mathrm{X} \mathrm{R}_{1}^{(1)}$ & & & $\begin{array}{l}33= \\
10\end{array}$ & \\
\hline & (4) & & & & $\begin{array}{l}\mathrm{M}_{3} \\
=1\end{array}$ & $\begin{array}{c}\mathrm{G}_{3} \\
= \\
10\end{array}$ & $\begin{array}{r}\mathrm{S}_{3} \\
=0\end{array}$ \\
\hline 4 & -1 & -1 & & & & & \\
\hline 0 & 7 & -5 & & & & & \\
\hline 0 & -1 & 5 & $\begin{array}{l}\mathrm{R}_{3}^{(4)}=\mathrm{R}_{3}^{(3)} / \\
10\end{array}$ & $\begin{array}{l}\mathrm{k}_{32} \\
=- \\
1 / 7\end{array}$ & $\begin{array}{c}M_{43} \\
=7\end{array}$ & & \\
\hline & $(5)$ & & & & $\begin{array}{l}M_{4} \\
=7\end{array}$ & $\begin{array}{c}\mathrm{G}_{4} \\
= \\
1\end{array}$ & $\begin{array}{l}\mathrm{S}_{4} \\
=0\end{array}$ \\
\hline 4 & -1 & -1 & & & & & \\
\hline 0 & 7 & -5 & & & & & \\
\hline
\end{tabular}


Journal of Advanced Research in Civil Engineering and Architecture, 1 (1):10-23, 2019

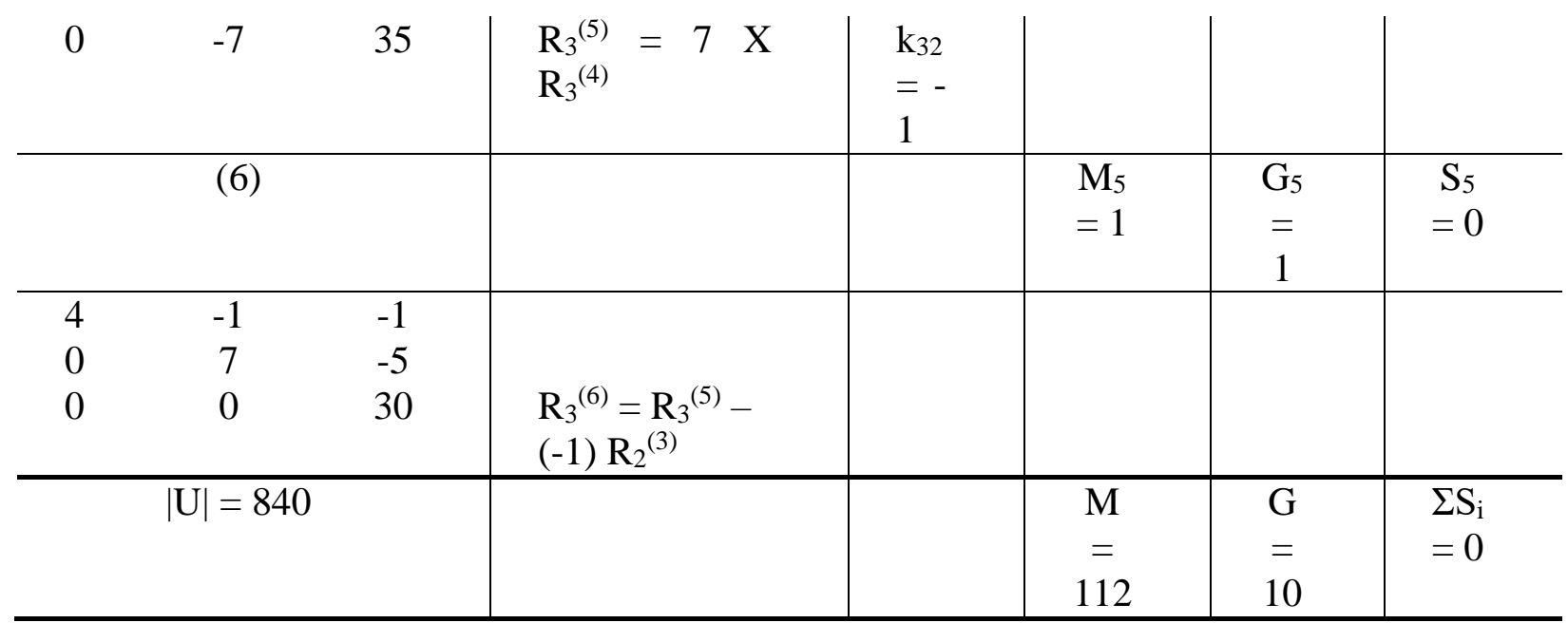

Since $\Sigma \mathrm{S}_{\mathrm{i}}=0$ then $\mathrm{S}=(-1)^{\sum \mathrm{s}_{\mathrm{i}}}=1$.

$$
\begin{aligned}
\mathrm{M} & =\prod_{i=1}^{n} M_{i}=112 . \\
\mathrm{G} & =10 \\
|\mathrm{~B}| & =\frac{\mathrm{S}|\mathrm{U}| \mathrm{G}}{\mathrm{M}}=\frac{1 \times 840 \times 10}{112}=75 \\
|\mathrm{~A}| & =20 \times 20 \times 10 \times|\mathrm{B}|=300000
\end{aligned}
$$

\begin{tabular}{|c|c|c|c|c|c|c|}
\hline \multicolumn{3}{|c|}{ (1) Determinant $|\mathbf{A}|$} & \multirow{2}{*}{$\begin{array}{l}\text { Notes } \\
\mathrm{R}_{1}{ }^{(1)}\end{array}$} & $\mathrm{k}$ & \multirow[t]{2}{*}{$\mathrm{M}$} & \multirow[t]{2}{*}{$\mathrm{S}$} \\
\hline 80 & -20 & -20 & & & & \\
\hline-20 & 40 & -20 & $\mathbf{R}_{2}^{(1)}$ & $\begin{array}{l}\mathrm{k}_{21}=- \\
20 / 80\end{array}$ & $\mathrm{M}_{12}=80$ & \\
\hline-20 & -20 & 130 & $\mathrm{R}_{3}^{(1)}$ & $\begin{array}{l}\mathrm{k}_{31}=- \\
20 / 80\end{array}$ & $\mathrm{M}_{13}=80$ & $\begin{array}{l}S_{1} \\
= \\
0\end{array}$ \\
\hline & $(2)$ & & & & $\begin{array}{l}M_{1}= \\
6400\end{array}$ & $\begin{array}{l}S_{1} \\
= \\
0\end{array}$ \\
\hline $\begin{array}{c}80 \\
-\end{array}$ & $\begin{array}{c}-20 \\
3200\end{array}$ & $\begin{array}{c}-20 \\
-1600\end{array}$ & $\mathrm{R}_{2}^{(2)}$ & $\mathrm{k}_{21}=-20$ & & \\
\hline $\begin{array}{c}160 \\
0\end{array}$ & & & $\begin{array}{l}=80 \\
X \\
R_{2}{ }^{(1)}\end{array}$ & & & \\
\hline $\begin{array}{c}- \\
160 \\
0\end{array}$ & -1600 & 10400 & $\begin{array}{l}\mathrm{R}_{3}{ }^{(2)} \\
=80 \\
\mathrm{X} \\
\mathrm{R}_{3}{ }^{(1)}\end{array}$ & $\mathrm{k}_{31}=-20$ & & \\
\hline & (3) & & & & $\mathrm{M}_{2}=1$ & $\begin{array}{l}\mathrm{S}_{2} \\
= \\
0\end{array}$ \\
\hline
\end{tabular}

For comparison the following is the solution of the same example without using GCD 


\begin{tabular}{|c|c|c|c|c|c|c|}
\hline $\begin{array}{c}80 \\
0\end{array}$ & $\begin{array}{c}-20 \\
2800 \\
-2000\end{array}$ & $\begin{array}{c}-20 \\
-2000 \\
10000\end{array}$ & $\begin{array}{l}\mathrm{R}_{2}{ }^{(3)} \\
= \\
\mathrm{R}_{2}{ }^{(2)} \\
-{ }^{\prime}(- \\
20) \\
\mathrm{R}_{1}{ }^{(1)} \\
\mathrm{R}_{3}{ }^{(3)} \\
= \\
\mathrm{R}_{3}{ }^{(2)}- \\
(-20) \\
\mathrm{R}_{1}^{(1)} \\
\end{array}$ & $\begin{array}{l}\mathrm{k}_{32}=- \\
2000 / 280 \\
0\end{array}$ & $\begin{array}{c}M_{33}= \\
2800\end{array}$ & \\
\hline & (4) & & & & $\begin{array}{l}\mathrm{M}_{3}= \\
2800\end{array}$ & $\begin{array}{l}\mathrm{S}_{3} \\
= \\
0\end{array}$ \\
\hline $\begin{array}{c}80 \\
0 \\
0\end{array}$ & $\begin{array}{c}-20 \\
2800 \\
- \\
560000 \\
0\end{array}$ & $\begin{array}{c}-20 \\
-2000 \\
2800000 \\
0\end{array}$ & $\begin{array}{l}\mathrm{R}_{3}{ }^{(4)} \\
=280 \\
0 \quad \mathrm{X} \\
\mathrm{R}_{3}^{(3)}\end{array}$ & $\begin{array}{l}\mathrm{k}_{32}=- \\
2000\end{array}$ & & \\
\hline & (5) & & & & $\mathrm{M}_{4}=1$ & $\begin{array}{l}\mathrm{S}_{4} \\
= \\
0\end{array}$ \\
\hline $\begin{array}{c}80 \\
0 \\
0\end{array}$ & $\begin{array}{c}-20 \\
2800 \\
0\end{array}$ & $\begin{array}{c}-20 \\
-2000 \\
2400000 \\
0\end{array}$ & $\begin{array}{l}\mathrm{R}_{3}{ }^{(5)} \\
= \\
\mathrm{R}_{3}{ }^{(4)} \\
-(- \\
2000) \\
\mathrm{R}_{2}{ }^{(3)}\end{array}$ & & & \\
\hline \multicolumn{3}{|c|}{$|\mathrm{U}|=5.376 \mathrm{E}+12$} & & & $\begin{array}{c}\mathrm{M}= \\
1792000 \\
0\end{array}$ & $\begin{array}{c}\mathrm{S} \\
\mathrm{i}= \\
0\end{array}$ \\
\hline
\end{tabular}

Since $\Sigma S_{i}=0$ then $S=(-1)^{\sum s_{i}}=1$.

$$
|\mathbf{A}|=\frac{\mathrm{S}|\mathbf{U}|}{\mathrm{M}}=\frac{11 \times 5.376 \mathrm{E}+12}{17920000}=300000
$$

\section{Conclusion}

The alternative technique to Gauss Elimination Method for Determinants presented in this research can be used to get exact determinants. There is no need to use pivoting (partial or complete) or scaling except when the main diagonal element $\mathrm{a}_{\mathrm{ii}}=0$. It is efficient, reliable, and can be applied for all types of square matrices. It can also be easily implemented by hand calculations with the aid of hand calculator. By this alternative technique we obtain a crucial decision whether the matrix is singular or ill-conditioned because it gives exactly zero value for the determinant of a singular matrix and a small value for ill-conditioned matrix. 


\section{Recommendations}

Constructing a software for this alternative technique to Gauss Elimination Method for Determinants: Integers Version

\section{References}

[1] V.D. Rao, Numerical Methods. New Age International (P) Ltd, New Delhi, 2010.

[2] G. Schay, A Concise Introduction to Linear Algebra. Springer Science+ Business Media, LLC., USA, 2012.

[3] H. Anton and C. Rorres, Elementary linear algebra: applications version. $11^{\text {th }}$ ed., John Wiley \& Sons, USA, 2014.

[4] W.Y. Yang, W. Cao, T.S. Chung and J.Morris, Applied Numerical Methods Using MATLAB. John Wiley \& Sons, USA, 2005.

[5] S.T. Karris, Numerical Analysis Using MATLAB and Excel. $3^{\text {rd }}$ ed., Orchard Publications, USA, 2007.

[6] J.D. Hoffman, Numerical Methods for Engineers and Scientists. $2^{\text {nd }}$ ed., Marcel Dekker, Inc. USA, 2001.

[7] R. L. Burden and J. D. Faires, Numerical Analysis. $9^{\text {th }}$ ed., Brooks/Cole, Cengage Learning, USA, 2011.

[8] Ed Overman, A MATLAB Tutorial, The Ohio State University, 2012.

[9] J.D. Faires and R.L. Burden, Numerical Methods. $3^{\text {rd }}$ ed., Brooks Cole, USA, 2002.

[10] M.J. Tobias, Matrices in Engineering Problems. Morgan \& Claypool, 2011.

[11] S.C. Chapra, Applied Numerical Methods with MATLAB for Engineers and Scientists. $3^{\text {rd }}$ ed., McGraw-Hill Companies, USA, 2012.

[12] T.M. Apostol, Calculus Volume II, Multivariable Calculus and Linear Algebra, with Applications to Differential Equations and Probability. $2^{\text {nd }}$ ed., John Wiley \& Sons, USA, 1969.

[13] P. Dawkins, Linear Algebra, 2007, http://tutorial.math.lamar.edu/terms.aspx.

[14] R.A. Beezer, A First Course in Linear Algebra. Robert A. Beezer, http://linear.ups.edu, 2008. 
[15] C. Zaiontz, Determinants and Simultaneous Linear Equations, Real Statistics Using Excel, 2014 http://www.real-statistics.com/matrices-and-iterative-procedures/determinants-andsimultaneous-linear-equations/

[16] A. Jeffrey, Advanced Engineering Mathematics. Harcourt/Academic Press, USA, 2002.

[17] C.B. Moler, Numerical Computing with MATLAB. Electronic edition, MathWorks, Inc., 2013, https://www.mathworks.com/moler/chapters.html

[18] C.D. Meyer, Matrix Analysis and Applied Linear Algebra, SIAM: Society for Industrial and Applied Mathematics, 2001.

[19] C.S. Daniel and C. de Boor, Elementary Numerical Analysis. $3^{\text {rd }}$ ed., McGraw-Hill Book Company, USA, 1980.

[20] J. DeFranza and D. Gagliardi, Introduction to Linear Algebra with Applications. McGraw-Hill Companies, Inc, USA, 2009.

[21] J. Kiusalaas, Numerical Methods in Engineering with Matlab. Cambridge University Press, USA, 2005. www.cambridge.org/9780521852883

[22] L.R. Scott, Numerical Analysis. Princeton University Press, USA, 2011.

[23] The MathWorks, Function Reference Volume 2: F - O. Version 7. The MathWorks, 2004b.

[24] W.H. Press, S.A. Teukolsky, W.T. Vetterling and B.P. Flannery, Numerical Recipes, The Art of Scientific Computing. $3^{\text {rd }}$ ed., Cambridge University Press, New York, 2007.

[25] D. J. Higham and N.J. Higham, MATLAB Guide. D. J. Higham and N. J. Higham, 2000.

[26] D.S. Watkins, Fundamentals of Matrix Computations. Second Edition, John Wiley \& Sons, Inc., New York, 2002.

[27] Ed Overman, A MATLAB Tutorial, The Ohio State University, 2012.

[28] S.N. Sivanandam, and V.R. Bai, A Computationally Simplified Numerical Algorithm for Evaluating a Determinant, In: Das V.V., Stephen J., Chaba Y. (eds) Computer Networks and Information Technologies, CNC 2011, Communications in Computer and Information Science, Vol 142. Springer, Berlin, Heidelberg, (2011), DOI https://doi.org/10.1007/978-3-642-19542615.

[29] The MathWorks, Function Reference Volume 1: A - E. Version 7, The MathWorks, 2004a. 